\title{
U.S. Geological Survey Earthquake Science Center
}

\section{Mission and Operational Overview}

The mission of the U.S. Geological Survey (USGS) Earthquake Science Center is to collect a wide range of data on earthquakes, faults, and crustal deformation; conduct research to increase our understanding of earthquake source processes, occurrence, and effects; and synthesize this knowledge into probabilistic seismic hazard assessments, aftershock forecasts, and ground-shaking scenarios for anticipated major earthquakes. We disseminate these data products, hazard assessments, and research discoveries to scientists, engineers, emergency managers, and the public.

With university and State partners, we operate the California Integrated Seismic Network and the Pacific Northwest Seismic Network, as well as geodetic networks throughout the western United States. We also lead the National Strong Motion Project and the ShakeAlert earthquake early warning (EEW) system; house renowned rock mechanics laboratories and deep borehole geophysics facilities; and conduct extensive geophysical, geologic, and paleoseismic investigations along active faults. We are funded primarily by the USGS Earthquake Hazards Program, with additional support from the USGS Volcano Hazards and Energy Resources Programs, other Federal and State agencies, private foundations, and public and private utilities and corporations.

\section{Earthquake Monitoring}

- We continuously monitor earthquakes in California, Oregon, and Washington to provide real-time earthquake information to State and Federal emergency managers, first responders, and the public. We use these data to develop accurate earthquake catalogues for hazard characterization and research. We operate the National Strong Motion Network to record strong ground motions and structural response during significant earthquakes throughout the United States. We also provide data to the USGS ShakeMaps and PAGER systems for rapid dissemination of information on earthquake shaking and damage forecasts.

- We are developing the ShakeAlert EEW system for the West Coast, in partnership with California Institute of Technology, University of California Berkeley, University of Oregon, University of Washington, University of Nevada Reno, Central Washington University, UNAVCO, and geological surveys and emergency management agencies in California, Oregon, and Washington. This system will provide rapid notification that an earthquake is occurring and give many people a few seconds to tens of seconds warning before shaking arrives. We are also researching crowd-sourced solutions to provide EEW internationally, through projects funded by the Office of U.S. Foreign Disaster Assistance.
Combined seismic and geodetic station operated by the USGS and UNAVCO (a nonprofit university-governed geodetic consortium) to monitor earthquakes and crustal deformation along the San Andreas Fault System. 


\section{Earthquake Hazard Assessments}

- Working with the USGS Geologic Hazards Science Center in Golden, Colo., and other partners, we help create probabilistic earthquake rupture forecasts and seismic hazard maps that indicate the likelihood of earthquake shaking exceeding a specified level over a given time span. These maps inform seismic provisions in building codes and are used by insurance companies to assess risk and by structural engineers to design earthquakeresilient structures.

- We create earthquake scenarios for major urban areas, combining fault rupture simulations with three-dimensional (3-D) seismic velocity models to forecast ground shaking from anticipated large earthquakes. These models are used by agencies and engineers for emergency preparedness and to assess and mitigate potential damage to buildings and infrastructure.

- We issue time-dependent aftershock forecasts after magnitude 5 or greater earthquakes throughout the United States and develop temporal and spatial aftershock forecasts for significant earthquakes elsewhere when requested.

- We study prehistoric surface-rupturing earthquakes, both onshore and offshore, to calculate long-term fault slip rates and recurrence intervals for large, damaging earthquakes.

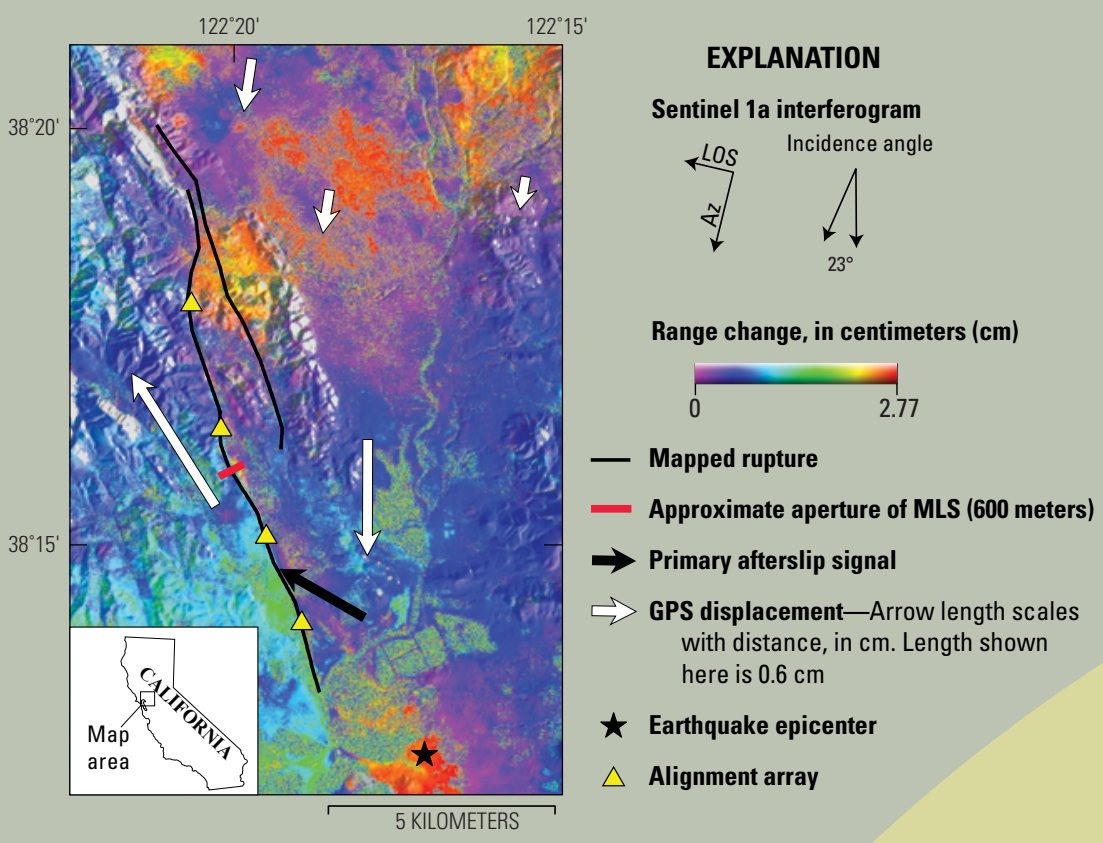

Map of ground deformation after the August 24, 2014, magnitude 6 South Napa earthquake, shown as the change in distance between the Earth's surface and the European Space Agency's Sentinel 1a synthetic aperture radar satellite (range change) from August 31 to 0 ctober 6, 2014. Slow fault slip (afterslip) continued for as much as one year after the earthquake and was measured using mobile laser scanning (MLS) and alignment arrays that crossed the mapped surface rupture. LOS, line of sight; Az, azimuth of satellite motion relative to the ground.

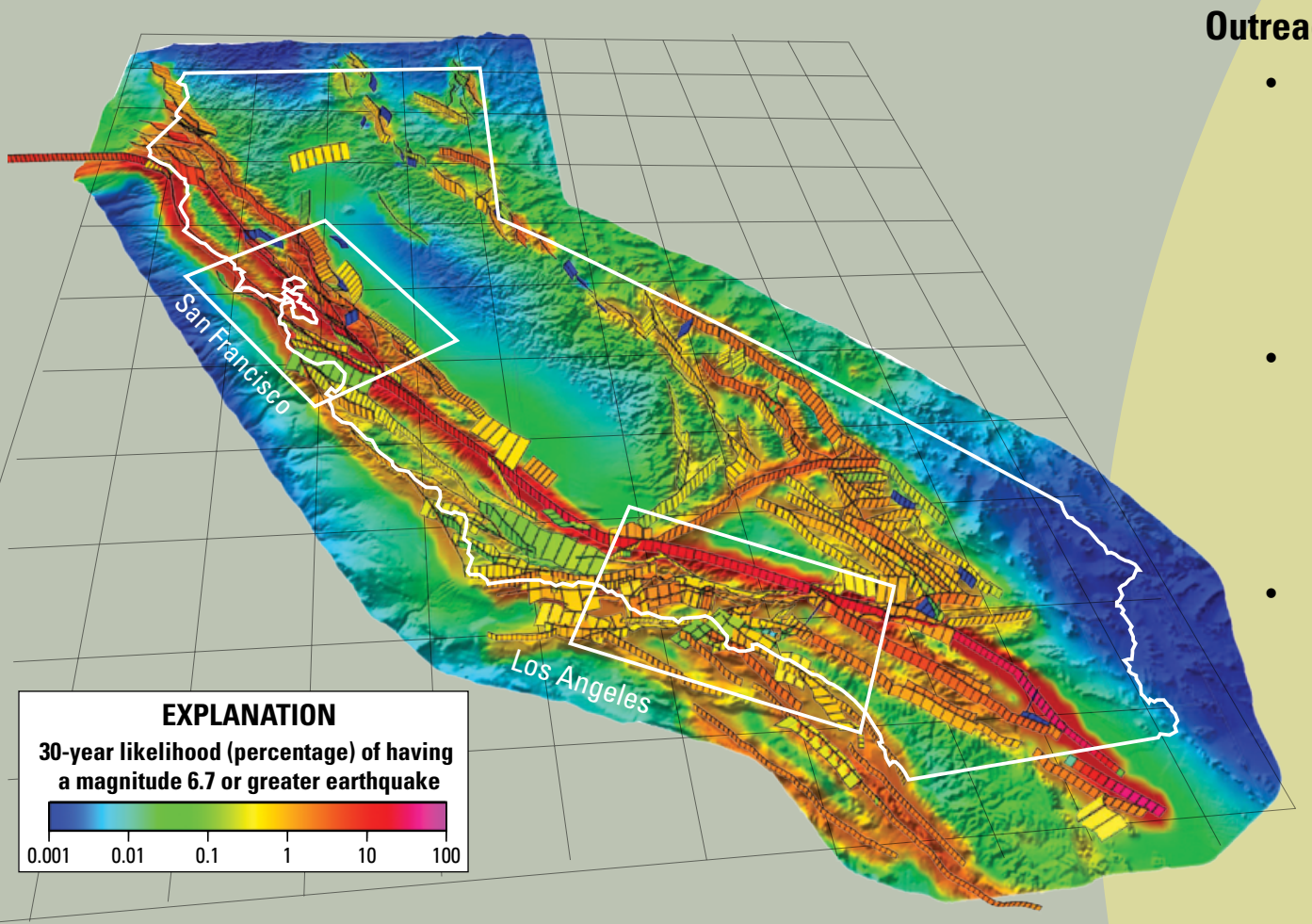

Three-dimensional perspective view of the likelihood that each region of California will experience a magnitude 6.7 or larger earthquake in the next 30 years, starting in 2014 (the 1994 Northridge earthquake was magnitude 6.7). This model (from the Uniform California Earthquake Rupture Forecast version 3, or UCERF3) incorporates the latest seismic, geologic, and geodetic data on California's complex system of active faults as well as new methods for translating these data into earthquake likelihoods.
- We are founding members of the Bay Area Earthquake Alliance and the Earthquake Country Alliance, which are private-public partnerships aimed at increasing earthquake resilience and preparedness throughout California.

- We give public talks on earthquake hazards and preparedness, mentor students and early career scientists, and advise local, State, and other Federal agencies on issues related to seismic hazards and risk mitigation.

We manage the communication, education, outreach, and technical engagement program for the ShakeAlert EEW system in California, Oregon, and Washington. 

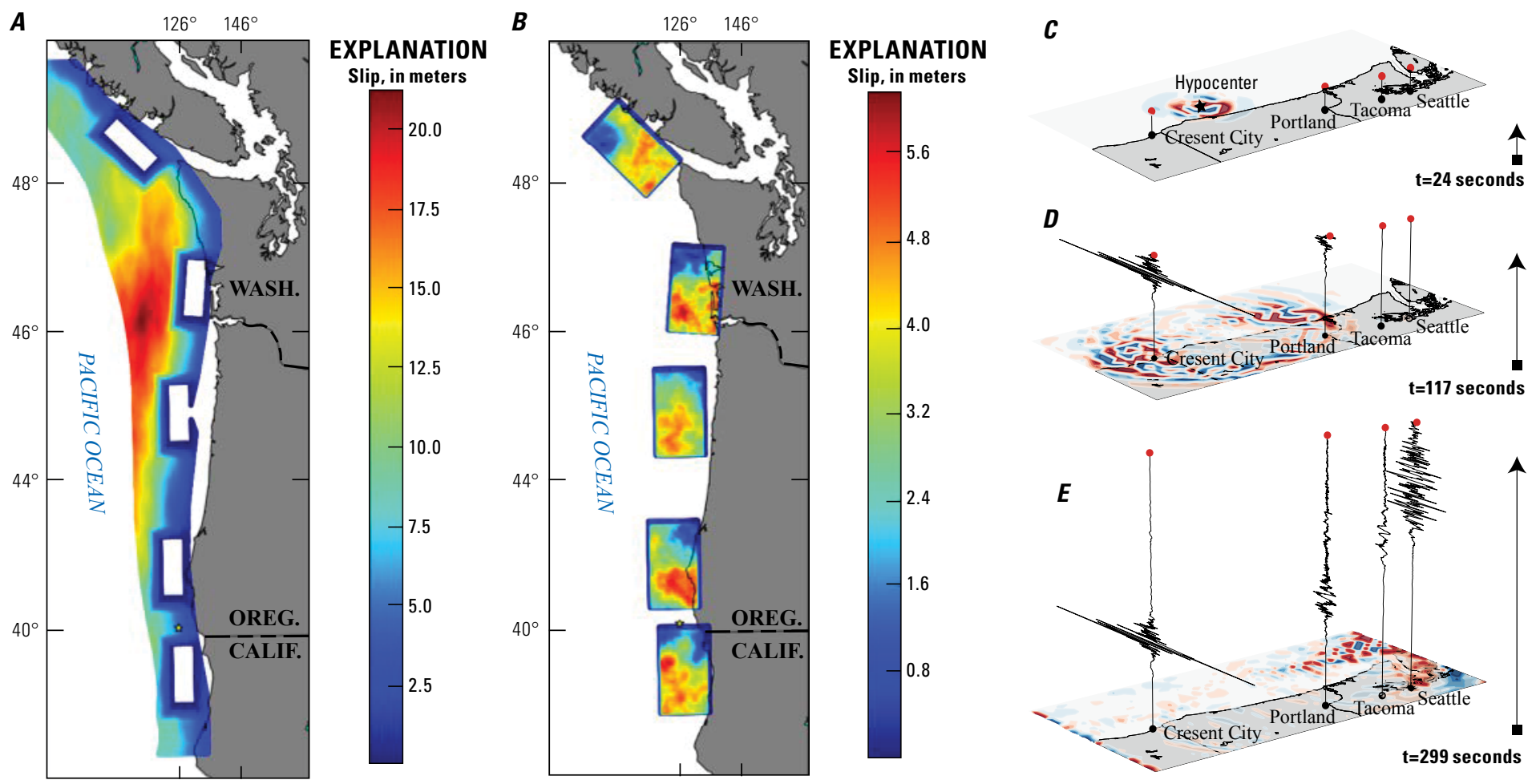

Distribution of fault slip assumed for computer models of shaking from great (magnitude 9) subduction zone earthquakes in Cascadia. $A$, Background slip; $B$, slip along high-strength patches (subevents). Subevent rupture generates the highest frequency and strongest ground motions. Projected above the map in $C, D$, and $E$, ground motions in cities are shown at three time (t) steps after the earthquake starts: 24, 117, and 299 seconds. Note the amplification of ground motion by soft sediments in the Seattle basin.

\section{Earthquake Research}

- We combine laboratory, seismological, geodetic, geologic, and borehole studies with theoretical models to better understand the physics of earthquakes. This allows us to address questions such as: Why do earthquakes occur in some places and not others? What factors control the timing and severity of earthquakes? Why do some earthquakes trigger other earthquakes? What makes some small earthquakes grow into larger ones?
- We conduct research on the role of local site conditions in controlling levels of earthquake shaking and damage, including amplification of shaking by sedimentary basins. We also study where and how earthquakeinduced ground failure (surface rupture, liquefaction, and landsliding) might be anticipated in order to reduce the resulting damage.

- We deploy temporary seismic networks and conduct research to understand how industrial activities, such as wastewater injection, can cause earthquakes. These studies are used to update USGS National Seismic Hazard Models and help industry modify their practices to minimize risks from induced seismicity.
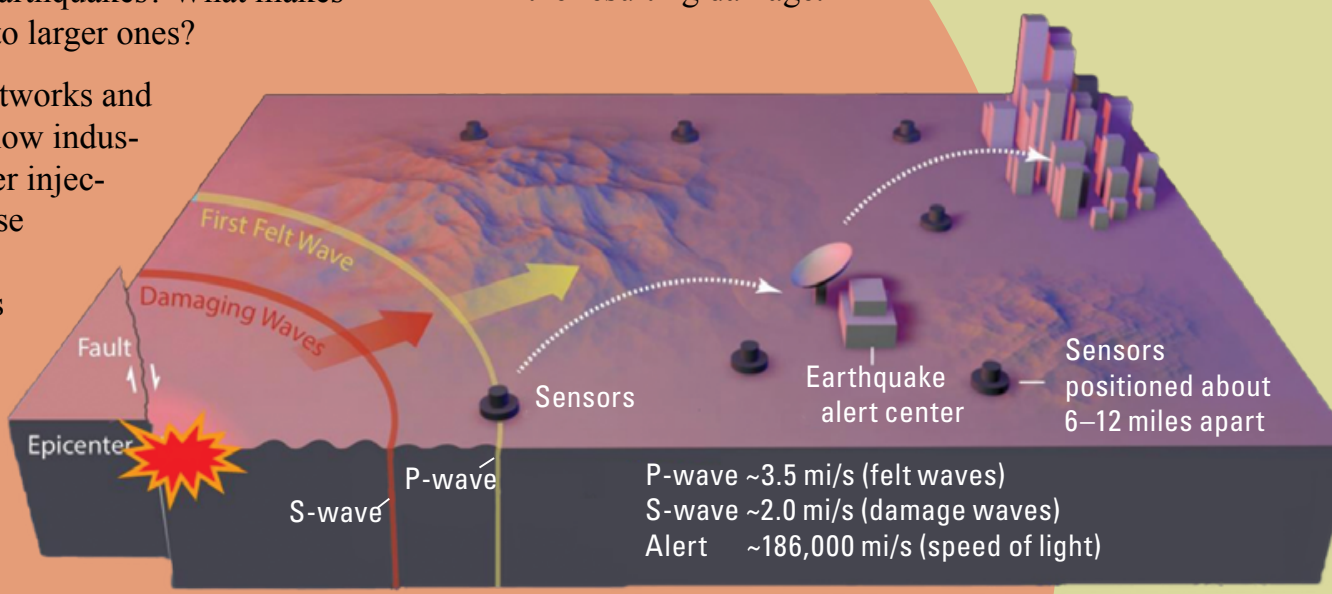

The ShakeAlert earthquake early warning system is based on the fact that a warning message can be transmitted almost instantaneously, while shaking from an earthquake travels through the Earth at speeds of a few miles per second (mi/s). When an earthquake occurs, seismic waves-including compressional $(\mathrm{P})$ and transverse $(\mathrm{S})$ waves-radiate outward from the fault rupture. The faster but (usually) weaker P-waves trigger sensors near the epicenter, causing alert signals to be sent out, giving many people and automated systems a few seconds to tens of seconds to take protective actions before the slower but stronger $\mathrm{S}$-waves arrive. 


\section{Staffing and Core Capabilities}

The $\sim 150$ employees of the Earthquake Science Center are located primarily in the San Francisco Bay region ( 120 people), with branches in Pasadena, Calif. ( 20 people), and Seattle, Wash. ( 10 people). Our principal areas of expertise are:

- $\quad$ Earthquake source seismology.-Physics of earthquake nucleation and rupture; fault stress interactions and triggering; statistical seismology and earthquake forecasting; episodic tremor and fault slip; earthquake swarms.

- Network operations.-Seismic and geodetic station installation, maintenance, telemetry, and data processing; rapid determination of earthquake source parameters and ground-motion levels; structural response monitoring; development, testing, and implementation of the ShakeAlert EEW system.

- Geodesy.-Usage of Global Positioning System (GPS), synthetic aperture radar, laser scanning, borehole strain, and other data to develop 3-D models of surface topography, crustal deformation, fault loading, and earthquake recurrence; incorporation of geodetic signals into EEW.

- Earthquake geology.-Fault trenching for earthquake recurrence; geologic mapping paired with fault displacement and geochronologic studies for slip rates; sedimentological studies of tsunami deposits; assessment of liquefaction and landslide potential.

- $\quad$ Seismic imaging. - Characterization of crustal properties, subsurface fault geometry, and structure using earthquakes, ambient noise tomography, and active-source seismology.

- $\quad$ Strong motion seismology.-Computer modeling of fault rupture, seismic wave propagation, and ground motions; development of empirical ground-motion prediction equations; probabilistic seismic hazard assessments; field studies of site amplification.

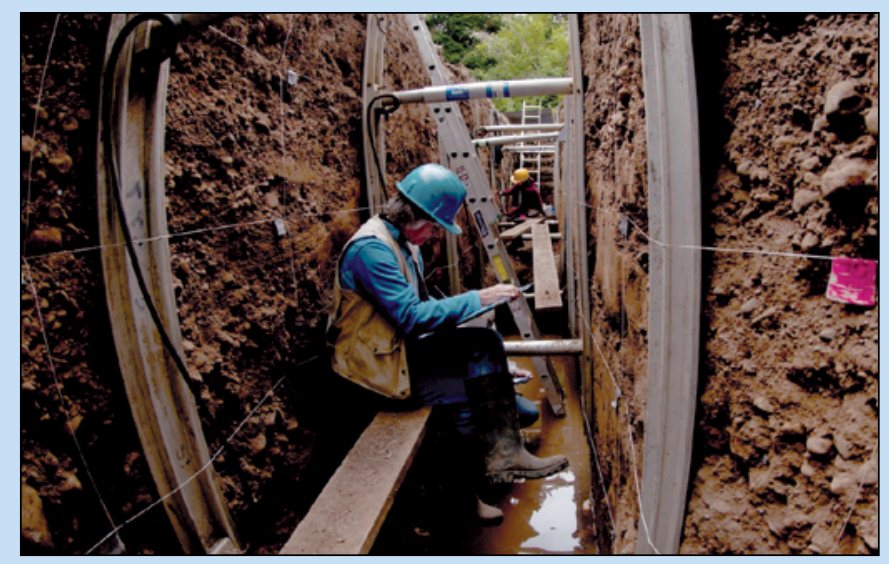

To assess the recurrence interval of major earthquakes on the San Andreas Fault, Earthquake Science Center scientists dug a trench across the fault to study the offset and age of soils that have been disrupted by prehistoric earthquakes.

- Laboratory rock mechanics.-High-pressure/ temperature experiments on frictional behavior and physical properties of fault rocks; meter-scale studies of earthquake nucleation, propagation, and arrest.

- Borehole geophysics.-Studies of stress, fracturing, and fluid flow in fault-hosted geothermal systems; deep drilling, sampling, measurements, and monitoring in active faults.

- Geomechanical modeling.-Computer studies of stress, deformation, fluid flow, and earthquake generation associated with oil and gas production, geothermal resource development, and $\mathrm{CO}_{2}$ sequestration.

- Communication, education, and outreach-Public engagement to enhance earthquake preparedness, personal safety, community resilience, and science education.

- Operational support.-Administrative and information technology support for a wide range of Science Center activities.

We leverage our capabilities by partnering with other Science Centers across the USGS, including the Geologic Hazards Science Center (Golden, Colo.), the Alaska Science Center (Anchorage), the Pacific Coastal and Marine Science Center (Santa Cruz, Calif.), the Geology, Minerals, Energy, and Geophysics Center (Menlo Park, Calif.) and various USGS Volcano Observatories, as well as scientists, engineers, and emergency managers from other agencies, universities, and research labs.

\section{By Stephen Hickman \\ Edited by Monica Erdman \\ Layout and design by Kimber Petersen}

For more information contact:

Stephen Hickman, Director, 650-439-2807, hickman@usgs.gov Keith Knudsen, Deputy Director, 650-439-2554, kknudsen@usgs.gov Earthquake Hazards Program, https://earthquake.usgs.gov

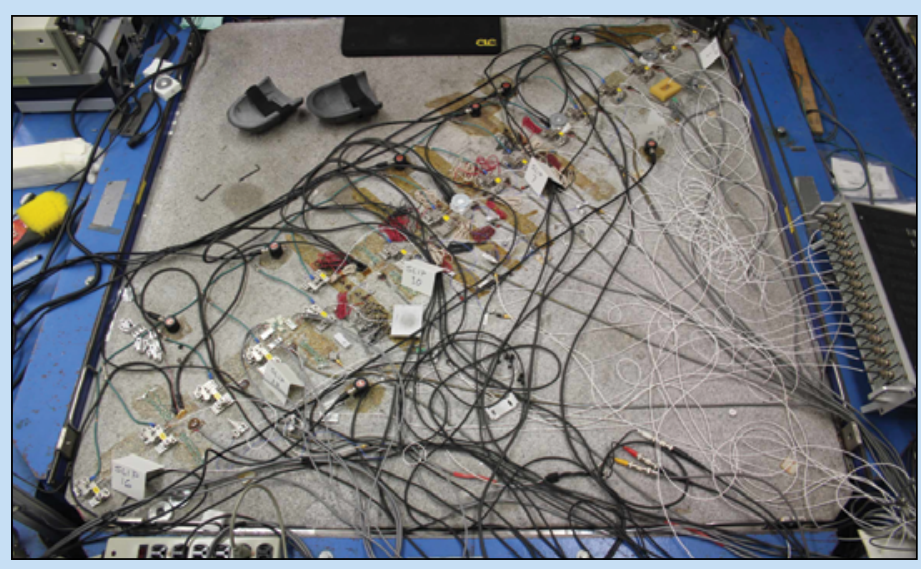

Earthquake Science Center scientists run experiments on this 5-foot-square granite block that contains a diagonal throughgoing fault to study the initiation, propagation, and arrest of earthquake ruptures under carefully controlled laboratory conditions. 